\title{
A study on micropropagation of Withania somnifera (L.) Dunal, Celastrus paniculatus (Willd.) and Pterocarpus santalinus
}

M. A. N. de Silva 


\title{
A study on micropropagation of Withania
}

\author{
somnifera (L.) Dunal, Celastrus \\ paniculatus (Willd.) and Pterocarpus \\ santalinus
}

BY

MURUKKUWADURA ACHALA NAYANI DE SILVA

Thesis submitted to the University of Sri Jayawardenapura for the award of the Degree of Master of Philosophy in Botany on Plant tissue culture 


\section{DECLARATION}

The work described in this thesis was carried out by me under the supervision of Dr. W.T.P.S.K. Senerath and Mr. G. de Silva, a report on this has not been submitted in whole or in part to any university for any other degree/Diploma.

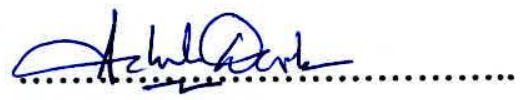

M. A. N. de Silva

$19(0.9 / 08$

B. Sc. (Agriculture)

Date 
We certify that the above statement made by the candidate is that true and this thesis is suitable for submission to the University of Sri Jayawardenapura for the purpose of evaluation.

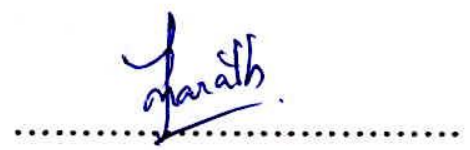

Dr. W. T. P. S.K. Senarath (Ph. D.)

Date:...19...................

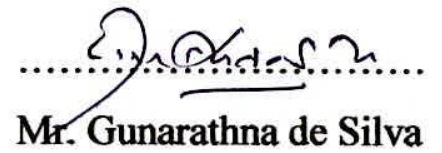

Date:...19...09.:.209.8 .

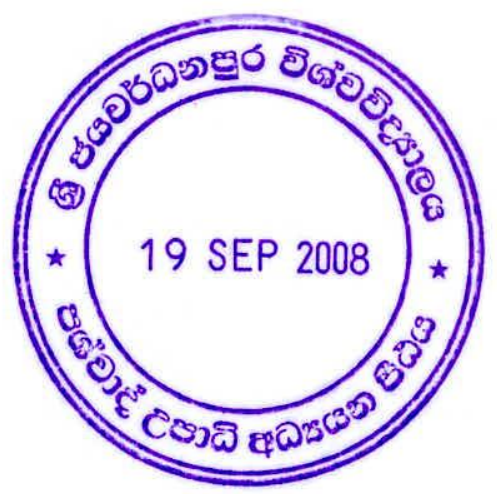




\section{TABLE OF CONTENTS}

\section{PAGE}

TABLE OF CONTENTS ................................................ I

LIST OF FIGURES......................................................... XII

LIST OF PLATES............................................................ XIII

LIST OF TABLES........................................................ XVI

ACKNOWLEDGEMENT ..................................................... XX

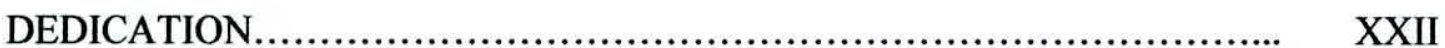

ABBREVIATIONS...................................................... XXIII

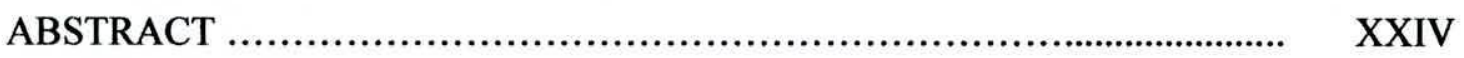

\section{CHAPTER 1: INTRODUCTION}

1.1 Celastrus paniculatus Willd. ............................. 1

1.1.1 Habit of Celastrus paniculatus ......................... $\quad 1$

1.1.2 Taxonomy and classification .......................... 3

1.1.3 Geographical distribution ........................... 3

1.1.4 Chemical composition and uses ........................ 3

1.1.5 Propagation methods ................................... 4

1.1.6 Importance of mass propagation of C. paniculatus through tissue culture................................... 5

1.1.7 Shoot tip necrosis ...................................... 6

1.2 Withania somnifera (L.) Dunal ............................... 6

1.2.1 Habit of Withania somnifera .............................. 7

1.2.2 Taxonomy and classification ............................ 8

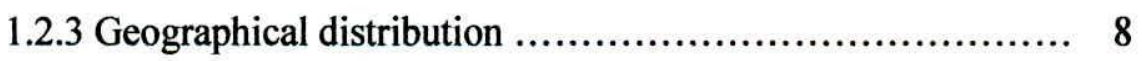

1.2.4 Chemical composition and uses ........................ 8 
1.2.6 Importance of mass propagation of $W$. somnifera

through tissue culture

1.3 Pterocarpus santalinus L. f.

1.3.1 Habit of $P$. santalinus 12

1.3.2 Taxonomy and classification ............................ 13

1.3.3 Geographical distribution............................. 13

1.3.4 Chemical composition and uses........................ 13

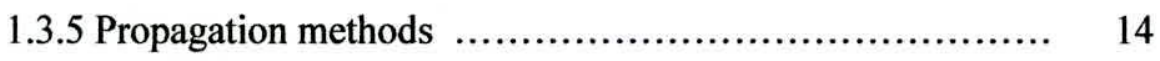

\subsubsection{Importance of mass propagation of $P$. santalinus} through tissue culture

1.4 Importance of comparable study between tissue cultured plants and seed raised plants

1.5 Thin Layer chromatography (TLC) and densitometry for comparison of chemicals in tissue cultured plants and seed raised plants

1.6 Objectives

\section{CHAPTER 2: LITERATURE REVIEW}

2.0 General

2.0.1 Sources of explants

a) Meristems

b) Leaf pieces 20

c) Nodal segments 22

d) Embryo culture 22 
2.0.2 Callus

2.0.3 Shoot induction ....................................... 24

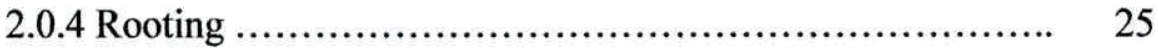

2.0.5 Somatic embryogenesis .................................................... 26

2.1 Celastrus paniculatus Willd............................... 28

2.1.1 Outline of tissue culture of Celastraceae $\ldots \ldots \ldots \ldots \ldots \ldots . . . . . . .28$

2.1.2 Tissue culture of $C$. paniculatus .......................... 28

2.2 Withania somnifera L. (Dunal) ........................... 30

2.2.1 Outline of tissue culture of Solanaceae $\ldots \ldots \ldots \ldots \ldots \ldots . . . . . . . . .30$

2.2.2 Tissue culture of Withania somnifera ..................... 31

2.3 Pterocarpus santalinus L. f. ............................. 34

2.3.1 Outline of tissue culture of Fabaceae .................... 34

2.3.2 Tissue culture of $P$. santalinus ......................... 35

\section{CHAPTER 3: MATERIALS AND METHODS}

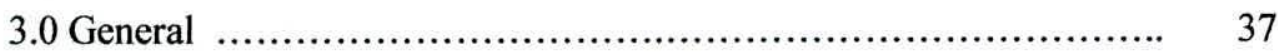

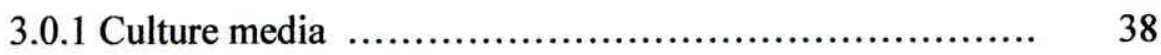

3.0.2 Preparation of stock solutions ........................ 38

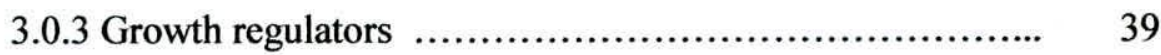

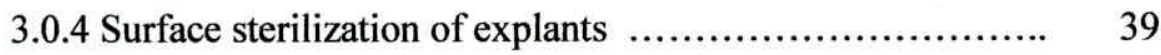

3.0.5 Experimental design $\ldots \ldots \ldots \ldots \ldots \ldots \ldots \ldots \ldots \ldots \ldots \ldots \ldots \ldots . \quad 40$

3.1 Celastrus paniculatus Willd. ............................. 40

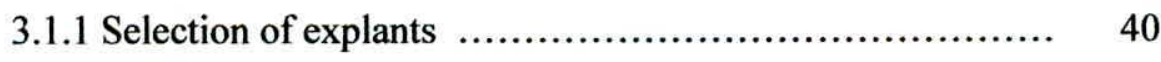


3.1.2 Selection of the suitable growth regulator combination for callus induction from different explants of $C$. paniculatus

3.1.3 Selection of suitable growth regulator combination for shoot initiation

3.1.4 Selection of suitable growth regulator combination for shoot multiplication.

3.1.5 Determination of the factors affecting STN in

C. paniculatus

3.1.5.1 Effect of Calcium level present in the medium on control of shoot tip necrosis

3.1.5.2 Effect of Boron level present in the medium on control of shoot tip necrosis

3.1.6 Selection of suitable growth regulator combination for root initiation of $C$. paniculatus 45

3.1.7 Determination of suitable potting mixture for acclimatization and greenhouse establishment of in vitro produced plants of C. paniculatus

3.1.8 Assessment of physiology, anatomy and growth of tissue cultured plants of $C$. paniculatus

3.1.8.1 Determination of the rate of photosynthesis

of in vitro produced C. paniculatus

3.1.8.2 Determination of the stomatal resistance

of in vitro produced $C$. paniculatus .48 
3.1.8.4 Determination of the growth of in vitro produced plants of $C$. paniculatus

\subsection{Withania somnifera (L) Dunal}

3.2.1 Determination of the rate of callus induction from different explants

3.2.2 Determination of suitable growth regulator combination for shoot proliferation and multiplication of $W$. somnifera

3.2.3 Determination of suitable growth regulator combination for root induction of $W$. somnifera.

3.2.4 Determination of the suitable potting mixture for acclimatization and greenhouse establishment of W. somnifera

3.2.5 Comparison of growth, physiology and anatomy of tissue cultured plants and seed raised plants

3.2.5.1 Comparison of the growth of tissue cultured plants with seed raised plants

3.2.5.2 Comparison of the rate of photosynthesis of tissue cultured plants and seed raised plants

3.2.5.3 Comparison of stomatal resistance of tissue cultured plants and seed raised plants after six months 54

3.2.5.4 Comparison of the anatomy of leaves and stem of tissue cultured plants with seed raised plants 
3.2.5.5 Comparison of chemical identities present in tissue cultured plants and seed raised plants of $W$. somnifera 55

3.3 Pterocarpus santalinus L. f. .................................... 56

3.3.1 Selection of explants ................................. 56

3.3.2 Selection of the suitable growth regulator combination for callus initiation from different explants .............. 57

3.3.3 Selection of the suitable growth regulator combination for shoot initiation

\section{CHAPTER 4: RESULTS}

4.1 Celastrus paniculatus Willd. 60

4.1.1 General 60

4.1.2 Selection of the suitable growth regulator combination for callus induction from different explants of $C$. paniculatus

4.1.3 Selection of suitable growth regulator combination for shoot initiation

4.1.4 Selection of suitable growth regulator combination for shoot multiplication

4.1.5 Determination of the factors affecting shoot tip necrosis (STN) in C. paniculatus

4.1.5.1. Effect of Calcium level present in the medium on control of STN

4.1.5.2 Effect of B level present in the medium on control of shoot tip necrosis 
4.1.6 Selection of suitable growth regulator combination for root initiation of C. paniculatus

4.1.7 Determination of suitable potting mixture for acclimatization and greenhouse establishmentof in vitro produced plants of C. paniculatus

4.1.8 Assessment of physiology, anatomy and growth of tissue cultured plants of $C$. paniculatus

4.1.8.1 Determination of the rate of photosynthesis of in vitro produced $C$. paniculatus

4.1.8.2 Determination of the stomatal resistance of in vitro

produced C. paniculatus

4.1.8.3 Study of the anatomy of in vitro produced plants 76

4.1.8.4 Determination of the growth of in vitro produced plants of C. paniculatus

4.2.1 Determination of the rate of callus induction from different

explants 79

4.2.2 Determination of suitable growth regulator combination for shoot proliferation and multiplication of $W$. somnifera 
4.2.3 Determination of suitable growth regulator combination for

root induction of $W$. somnifera

4.2.4 Determination of the suitable potting mixture for

acclimatization and green house establishment

of in vitro propagated plants of $W$. somnifera

4.2.5 Comparison of growth, physiology and anatomy of tissue cultured plants and seed raised plants

4.2.5.1 Comparison of the growth of tissue cultured plants with seed raised plants

4.2.5.2 Comparison of the rate of photosynthesis of tissue cultured plants and seed raised plants

4.2.5.3 Comparison of stomatal resistance of tissue cultured plants and seed raised plants after six months

4.2.5.4 Comparison of the anatomy of leaves and stem of tissue cultured plants with seed raised plants

4.2.5.5 Comparison of chemical identities present in tissue cultured plants and seed raised plants of W. somnifera

4.3 Pterocarpus santalinus L.f. 98

4.3.1 General 98

4.3.2 Selection of the suitable growth regulator combination for callus initiation from different explants 
4.3.3 Selection of the suitable growth regulator combination for shoot initiation

\section{CHAPTER 5: DISCUSSION}

5.1 Celastrus paniculatus Willd.

5.1.1 General

5.1.2 Selection of suitable growth regulator combination for callus induction from different explants of $C$. paniculatus

5.1.3 Selection of suitable growth regulator combination for shoot initiation

5.1.4 Determination of suitable growth regulator for shoot multiplication

5.1.5 Determination of the factors affecting STN in C. paniculatus 108

5.1.5.1. Effect of Calcium level present in the medium on control of shoot tip necrosis

5.1.5.2. Effect of Boron level present in the medium on control of shoot tip necrosis 109

5.1.6 Selection of the suitable growth regulator combination for root initiation of C. paniculatus. 110

5.1.7 Determination of a suitable potting mixture for acclimatization and growing of in vitro produced plants of $C$. paniculatus ... 111

5.1.8 Assessment of physiology, anatomy and growth of tissue cultured plants of C. paniculatus 
5.1.8.1 Determination of the rate of photosynthesis of in vitroProduced $C$.paniculatus

5.1.8.2 Determination of the stomatal resistance of in vitro produced C. paniculatus

5.1.8.3 Study of the anatomy of in vitro produced plants 113

5.1.8.4 Determination of growth of in vitro produced plants of C. paniculatus

5.2 Withania somnifera L (Dunal)

5.2.1 Determination of callus induction from different explants .... 114

5.2.2 Determination of suitable growth regulator combination for shoot proliferation and multiplication of $W$. somnifera

5.2.3 Determination of suitable growth regulator combination for rootinduction of $W$. somnifera.

5.2.4 Determination of suitable potting mixture for acclimatization and green house establishment of in vitro propagated plants of $W$. somnifera

5.2.5 Comparison of growth, physiology and anatomy of tissue cultured plants and seed raised plants of $W$. somnifera

5.2.5 1 Comparison of growth of tissue cultured plants and seed raised plants of $W$. somnifera 118

5.2.5.2 Comparison of rate of photosynthesis of tissue cultured plants and seed raised plants of $W$. somnifera 119 
5.2.5.3 Comparison of stomatal resistant of tissue cultured plants and seed raised plants of

5.2.5.4 Comparison of anatomy of leaves and stem of tissue cultured plants and seed raised plants

5.2.5.5 Comparison of chemical identities present in tissue cultured plants and seed raised plants of W. somnifera

5.3 Pterocarpus santalinus L. f.

5.3.1 General

5.3.2 Selection of suitable growth regulator combination for callus initiation from different explants

5.3.3 Selection of suitable growth regulator combination for shoot initiation of $P$. santalinus

CHAPTER 6: CONCLUSION

6.1 Celastrus paniculatus Willd.

6.2 Withania somnifera L. (Dunal) 128

6.3 Pterocarpus santalinus L. f. 130

6.4 Recommendation for future work 131

REFERENCES 132 APPENDICES 


\section{LIST OF FIGURES}

Figure 1: Densitometric charts of two samples (a) seed raised plants

Page

(b) tissue cultured plants (c) both samples in same chart ............ 97 


\section{LIST OF PLATES}

\section{Page}

Plate 1: A mature plant of Celastrus paniculatus .............................. 2

Plate 2: Seeds of Celastrus paniculatus................................... 2

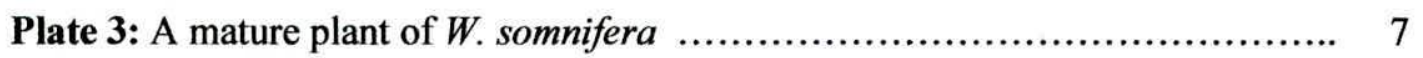

Plate 4: Mature plant of $P$. santalinus ..................................... 12

Plate 5: Colour and texture of the calli obtained from (a) Shoot tips

(b) Nodal segments and (c) Leaf pieces ............................ 61

Plate 6: Shoot initiation from (a) shoot tips (b) nodal segments ....................... 62

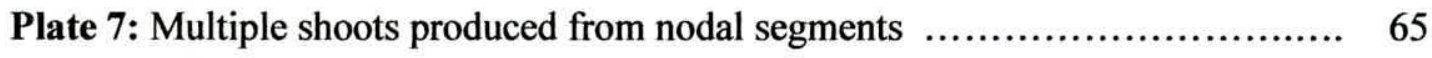

Plate 8: Shoot tip necrosis present in C. paniculatus in vitro plants ............... 67

Plate 9: (a) Rooted plants of C. paniculatus, (b) plants taken out before being

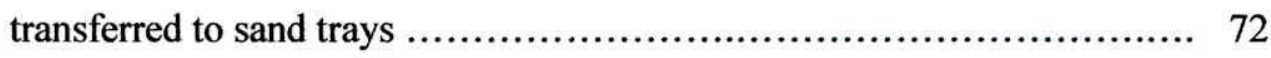

Plate 10: Humid chamber used to acclimatize plants .......................... 73

Plate 11: . paniculatus plants transferred in to sterilized sand tray ................. 73

Plate 12: Cross section of a leaf of ( a) tissue cultured plant and

(b) cross section of a seed raised plant $(1 \times 4 \times 10) \ldots \ldots \ldots \ldots \ldots \ldots \ldots \ldots . . . \ldots \ldots$

Plate 13: Cross section of a stem of (a) tissue cultured plant and

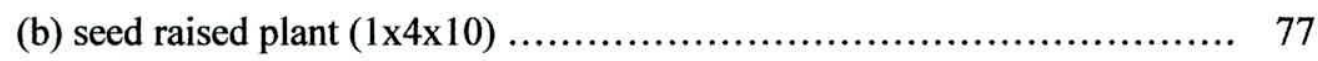

Plate 14: Acclimatized plants of $C$. paniculatus ............................. 79 
Plate 15: (a) Callus and shoot initiation from shoot tips

Plate 16: Multiple shoots produced from callus obtained from nodal

segments of $W$. somnifera 84

Plate 17: Elongated multiple shoots of $W$. somnifera 85

Plate 18: Acclimatized (a) tissue cultured and (b) seed raised plants of $W$. somnifera

Plate 19: Cross section of leaf of (a) tissue cultured plant

(b) seed raised plant (mag, $1 \times 4 \times 10)$ 92

Plate 20: Cross section of stem of (a) tissue cultured plant,

(b) cross section of a seed raised $W$ somnifera plant $(1 \times 4 \times 10)$ 92

Plate 21: (a) Running of two samples in solvent system (b) TLC finger print for two samples after spraying vanillin sulfate (TC-Tissue cultured, SR- seed raised) 94

Plate 22: TLC finger print for samples T- tissue cultured plants,

S- seed raised plants, W-Standard withaferine A and R-available sample of root extract of $W$. somnifera at ITI 95

Plate 23: (a) Callus initiation from nodal segments (b) Shoot initiation from nodal segments (c) callus growing in liquid medium 101 
Plate 24: Green colour callus produced from nodal segments (a) in liquid

Medium (b) growth and colour change of callus with time 102

Plate 25: Cells obtained from callus under light microscope

(a) embryogeneic mucilage callus from nodal segments

(b) green colour vegetative callus $(1 \times 10 \times 10)$ 102

Plate 26: Callus cells obtained from (a) shoot tip explants, (b) leaf explants and (c) nodal segment explants under light microscope $(1 \times 20 \times 10)$ 106 


\section{LIST OF TABLES}

Table 1: Growth regulator combinations used to determine the suitable growth regulator combination for callus induction

Table 2: Growth regulator combinations tested for shoot initiation

Table 3: Growth regulator combinations tested for shoot multiplication of C. paniculatus

Table 4: Different Calcium concentrations used in experiment.

Table 5: Different Boron concentrations used in experiment

Table 6: Growth regulator combinations tested for root induction

of C. paniculatus

Table 7: Different potting mixtures tested for acclimatization

Table 8: Different growth regulator combinations tested for callus initiation of $W$. somnifera

Table 9: Different BAP concentrations tested for shoot proliferation and multiplication of W. somnifera

Table 10: Different growth regulator combinations tested for root initiation

Table 11: Different potting mixtures tested for acclimatization and greenhouse establishment

Table 12: Different growth regulator combinations tested for callus initiation from nodal segments and shoot tips of $P$. santalinus

Table 13: Different growth regulator combinations tested for callus initiation of leaf pieces of $P$. santalinus 
Table 14: Growth regulator combinations tested for shoot initiation

Table 15: Callus induction from nodal segments after 6 weeks of incubation...

Table 16: Shoot initiation from nodal segment explants after 6 weeks of incubation. Twenty replicates per treatment

Table 17: Shoot initiation from shoot tip explants after 6 weeks of incubation. Twenty replicates per each treatment

Table 18: Multiple shoot induction in different culture media after 6 weeks 65

Table 19: Effect of Calcium level present in the medium on control of shoot tip necrosis after 10 weeks in STN (-)

Table 20: Effect of Ca level present in the medium on control of shoot tip necrosis after 10 weeks in STN $(+)$ 68

Table 21: Effect of B level present in the medium on control of shoot tip necrosis after 10 weeks in STN (-)

Table 22: Effect of B level present in the medium on control of shoot tip necrosis after 10 weeks in STN $(+)$

Table 23: Root initiation from shoots after 6 weeks of incubation. 71

Table 24: Percentage survival of in vitro produced plants of $C$. paniculatus in different types of potting mixtures 73

Table 25: Rate of photosynthesis of tissue cultured plants of C. paniculatus after three and six months

Table 26: Mean stomatal resistance at three months and six months 75 
Table 27: Plant height, number of leaves and number of branches per plant

in tissue cultured plants over six months

Table 28: Callus induction in leaf explant in different growth regulator

combinations after four weeks

80

Table 29: Callus induction from nodal segment of $W$. somnifera in

different growth regulator combinations after 4 weeks

Table 30: Callus induction in shoot tip explants, in different growth

regulator combinations

Table 31: Shoot multiplication in callus obtained from nodal segments of

W. somnifera

Table 32: Shoot multiplication from callus obtained from shoot tip explants

of $W$. somnifera

Table 33: Root production of $W$. somnifera, in different growth regulator

Combinations

Table 34: Percentage survival of in vitro propagated plants of $W$. somnifera after two months. 
Table 35: Plant height, number of leaves and number of branches per plant in tissue cultured plants for six months.

Table 36: Plant height, number of leaves and number of branches per plant of seed raised plants for six months

Table 37: Rate of photosynthesis of $W$. somnifera after three months

Table 38: Rate of photosynthesis after six months

Table 39: Mean stomatal resistance at six months

Table 40:

(a) : Callus induction from nodal segments and shoot tips in different growth regulator combinations after six weeks

(b) : Callus induction from leaf pieces in different growth regulator combinations after 6 weeks 100 


\section{ACKNOWLEDGEMENT}

I express my sincere gratitude and appreciation to my internal supervisor Dr WTPSK Senarath, Senior Lecturer of the Department of Botany University of Sri Jayawardanapura for her guidance help and critical comments for the completion of the thesis. I am grateful to Mr. Gunarathna de Silva, former Senior Scientist (Botany), Bandaranaike Memorial Ayurvedic Research Institute, Nawinna for encouraging me to initiate and carry out this research work at BMARI.

My sincere gratitude is also extended to Ms. Sudeepa Sugathadasa, Scientist (Pharmacognocy), BMARI for her encouragement, comments and valuable guidance through out the research work.

I must thankful to Prof. Ajith Abeysekara, former Director of BMARI for providing a chance for me to carry out this research work at BMARI and my thanks are also extended to Prof. P K Smarakoon, Director of BMARI for his encouragement. I must express my sincere thanks to Mrs. Ramani Gunawardone, Commissioner of Ayurveda.

I would like to express my sincere thanks to Dr. Sirimal Premakumara, Head, Natural production division, and Ms. Menuka Arawwala, Research Officer, Natural production division of the Industrial Technology Institute for their guidance and kind help for me to carryout the chemical screening at ITI.

My special thank is given to Ms Udeshika Kaluarachchi, Laboratory Assistant, BMARI and Mr. N Wijaya Raja and Mr. K D Chandana, minor staff of the BMARI for various help given to me for success of this work. 
I would like to thank Mr. R Kandambi, Senior technical Officer, Department of Botany, University of Sri Jayawardanapura for his assistance and Mr. Dimuthu Indika, Thechnical Officer, Department of Botany, University of Colombo for his help.

I extend my special thanks for Ms. Samangi Hewage, Ms. Anuja Udayakumari and Mr Sanka Ganegama for their various help given to me. I would like to thank all the staff members of the Botany Division, BMARI for their encouragement in completion of this work.

Finally I offer my true and cordial gratitude to my mother, brothers and sister for their encouragement and help given to me in various ways to carryout this research work up to success. 
DEDICATION

To my parents, Sister, brothers and beloved teachers 


\section{ABBREVIATIONS}

BAP - 6-benzylaminopurine: BA

2,4-D ～- 2,4 dichlorophenoxy acetic acid

IBA - Indole-3-butyric acid

IAA - indole-3-acetic acid

Kin - Kinetin

NAA $\quad-\quad \alpha$-napthaleneacetic acid

MS - $\quad$ Murashige and Skoog's (1962) medium

WPM - Woody plant medium

B $_{5} \quad$ - Gamberg's medium 


\title{
A study on micropropagation of Withania somnifera (L.) Dunal, Celastrus paniculatus (Willd.) and Pterocarpus santalinus \\ M.A.N. de Silva
}

\begin{abstract}
Celastrus paniculatus Willd. (Sin: Duhudu, San: Jyotishmathi) which belongs to family Celastraceae which seeds provide extremely important medicinal oil which is reported to be sharpening the memory and used as a treatment for number of diseases.C. paniculatus is listed as a highly threatened medicinal plant in Red data book published by IUCN in 1999. Withania somnifera (L.) Dunal (Sin: Amukkara, San: Ashwaganda) is a valuable medicinal plant, belongs to the family Solanaceae. W. somnifera is normally propagated by seeds however the wall of the fruit contains a chemical which prevent seed germination. However local cultivar of $W$. somnifera is also in Red list as a threatened plant. Pterocarpus santalinus (Sin: Rath handun, San: Raktha chandana) is also a medicinal plant with high demand.

The objective of this study was to develop successful protocols for in vitro mass propagation of Celastrus paniculatus, Withania somnifera and Pterocarpus santalinus, to acclimatize in vitro propagated plants and compare tissue cultured plants with seed raised plants based on growth, physiology and anatomy.

In the present study nodal segments, shoot tips and leaf pieces were used as explants in different growth regulator combinations (auxines and cytokinines) in order to produce callus, shoots and roots of the selected three plant species. In C. paniculatus all tested explants produce callus and the best explant for callus production was leaf pieces. It was
\end{abstract}


found that the best medium for callus production in all explant types was MS medium supplemented with 5.0 $\mu \mathrm{M}$ BAP and 7.0 $\mu \mathrm{M}$ IAA. Both shoot tips and nodal segments also have the possibility to produce shoots while nodal segments also showed better results than shoot tips. MS medium supplemented with $10.0 \mu \mathrm{M}$ BAP and $14.0 \mu \mathrm{M}$ IAA was found to be the best medium for shoot initiation and MS medium supplemented with $5.0 \mu \mathrm{M}$ BAP and $0.5 \mu \mathrm{M}$ IAA was the best for multiple shoot production $(8.3 \pm 0.60)$ among the tested treatments.

Shoot tip necrosis was observed in in vitro cultures of $C$. paniculatus when they elongated to more than $5.0 \mathrm{~cm}$ height and $3-5$ weeks in culture medium. The disorder was controlled by addition of $12.0 \mathrm{mM}$ Calcium or $50.0 \mu \mathrm{M}$ Boron into the shoot multiplication medium. Highest rooting (73.3\%) was obtained in MS medium supplemented with $5.6 \mu \mathrm{M}$ IAA and 9.6 $\mu \mathrm{M}$ IBA. In vitro produced plants of $C$. paniculatus were acclimatized in a potting mixture of river sand: top soil: compost 1:1:1 ratio which gave highest survival rate (75\%) among the other tested potting mixtures. Rate of photosynthesis and stomatal resistance of in vitro produced plants increased with time $(5.66 \pm 3.0,6.01 \pm 0.3$ respectively for 3 months and 6 months) indicating that plants had adapted to the normal environment. Growth of the acclimatized plants had a sigmoid pattern of normal growth. No significant difference was observed anatomically when cross section of leaf and stem were observed under light microscope.

In $W$. somnifera also all tested explants produced calli and best callus production was observed in MS medium supplemented with $1.0 \mu \mathrm{M}$ Kin, $4.5 \mu \mathrm{M}$ BAP, and 1.5 $\mu \mathrm{M}$ NAA under 14 days dark period. Shoot initiation was observed in the same medium from the 
calli produced from shoot tips and nodal segments. Highest shoot multiplication was observed in MS medium supplemented with $9.0 \mu \mathrm{M}$ BAP and $1.0 \mu \mathrm{M}$ IAA. Callus produced from leaf pieces did not respond in any medium to produce shoots. No significant difference was observed among tested treatments for rooting, suggesting growth regulator free MS medium was the best medium for rooting of $W$. somnifera. In vitro produced plants were acclimatized successfully in a potting mixture of river sand river sand: top soil: compost, 2: 1: 1 ratio. Rate of photosynthesis was higher in tissue cultured plants at three months and six months compared to seed raised plants. TLC finger prints and denitometry was used to compare chemical identities (steroids considered) and it was found that there was no significant difference in chemical identities present in tissue cultured and seed raised plants.

From the experiments conducted for $P$. santalinus only callus induction was successful and no shoots were induced through calli. According to the results best explant source for callus production were nodal segments. Highest callus production was observed from shoot tips and nodal segments in MS medium supplemented with $2.0 \mu \mathrm{M} \mathrm{BAP}, 0.5 \mu \mathrm{M}$ NAA and $1.5 \mu \mathrm{M}$ IBA. Callus growth continued when they were transferred into liquid medium as well. MS medium supplemented with $9.0 \mu \mathrm{M} 2,4-\mathrm{D}$ and $1.0 \mu \mathrm{M}$ BAP with calcium panthothenate $\left(100.0 \mathrm{mg} \mathrm{L}^{-1}\right)$ and coconut water $\left(100 \mathrm{ml} \mathrm{L}^{-1}\right)$ was the best for callus production from leaf pieces. Two types of calli were observed as vegetative and elongated embryogenic cells. Study should be continued further to produce shoots or somatic embryos from the calli. 